Check for updates

Cite this: Chem. Sci., 2019, 10, 252

๑ All publication charges for this article have been paid for by the Royal Society of Chemistry

\section{A cheap metal for a challenging task: nickel- catalyzed highly diastereo- and enantioselective hydrogenation of tetrasubstituted fluorinated enamides $\uparrow$}

\author{
Yu-Qing Guan, ${ }^{a}$ Zhengyu Han, ${ }^{a}$ Xiuxiu Li, ${ }^{a}$ Cai You, ${ }^{a}$ Xuefeng Tan, ${ }^{b}$ Hui Lv (D) *acd \\ and Xumu Zhang iD b
}

\begin{abstract}
Nickel-catalyzed asymmetric hydrogenation of challenging tetrasubstituted fluorinated enamides has been achieved, affording chiral $\alpha$-fluoro- $\beta$-amino esters in high yields with excellent diastereo- and enantioselectivities (up to $98 \%$ yield, >99: $1 \mathrm{dr}$, up to >99\% ee). Deuterium-labeling experiments and control experiments were conducted to probe the mechanism, and the results indicated that the acidity of the solvent plays a critical role in the control of diastereoselectivity by trapping the adduct of nickel hydride to $\mathrm{C}=\mathrm{C}$ bonds via protonolysis, giving the hydrogenation product with stereospecific synselectivity. This protocol provides efficient access to chiral $\alpha$-fluoro- $\beta$-amino esters which have important potential applications in organic synthesis and medicinal chemistry.
\end{abstract}

Received 9th September 2018 Accepted 3rd October 2018

DOI: $10.1039 / \mathrm{c} 8 \mathrm{sc} 04002 \mathrm{~h}$

rsc.li/chemical-science experienced rapid development, such as iron-, cobalt- and nickel-catalyzed asymmetric (transfer) hydrogenation of $\mathrm{C}=\mathrm{C}$, $\mathrm{C}=\mathrm{O}$, and $\mathrm{C}=\mathrm{N}$ bonds. ${ }^{3-5}$ However, first-row transition metal catalyzed asymmetric hydrogenation of tetrasubstituted alkenes has not been achieved.

Owing to the unique ability of fluorine to modulate the physical and biological properties of organic molecules, ${ }^{6}$ introduction of fluorine atoms to nitrogen-containing molecules has emerged as an attractive strategy in drug discovery, ${ }^{7}$ and a series of synthetic molecules containing chiral vicinal fluoroamine motifs, such as MK-0731, ${ }^{8 a}$ clofarabine,${ }^{8 b}$ and sitafloxacin ${ }^{8 c}$ (Fig. 1a), have been reported to exhibit important bioactivities. However, asymmetric synthetic routes to $\beta$-fluoroamines with a vicinal stereogenic center are still very limited, ${ }^{9-11}$ and most of them involve the formation of $\mathrm{C}-\mathrm{F}$ bonds and $\mathrm{C}-\mathrm{N}$ bonds. As an alternative approach, transition metal catalyzed asymmetric hydrogenation of tetrasubstituted fluorinated enamides, one of the most powerful transformations available in synthetic chemistry, ${ }^{12}$ is unexploited. There are several reasons that may account for the absence of asymmetric hydrogenation in this transformation. Firstly, the combined effect of both the steric hindrance and electron-deficient nature of tetrasubstituted fluorinated alkenes greatly decreases the coordination ability of the alkene to the metal, which leads to the low activity in asymmetric hydrogenation. ${ }^{12}$ Secondly, the competition between defluorination and hydrogenation makes this reaction more challenging. ${ }^{13}$ Especially, the reaction might be further challenged by relatively low catalytic activity when a nickel complex is employed as the catalyst. Moreover, the mechanism of Ni-catalyzed hydrogenation is distinct from the rhodium dihydride and ruthenium 


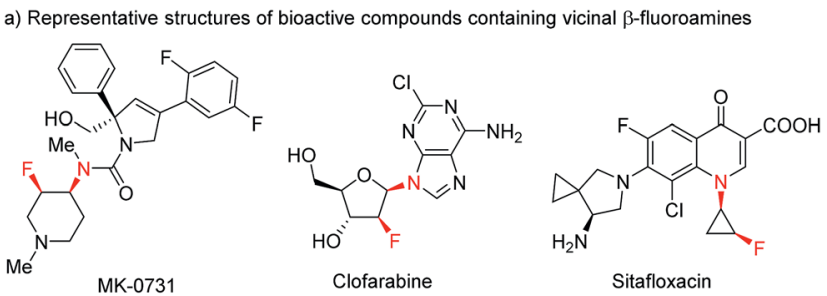

b) Nickel-catalyzed non syn-selective hydrogenation of trisubstituted alkenes (previous work)

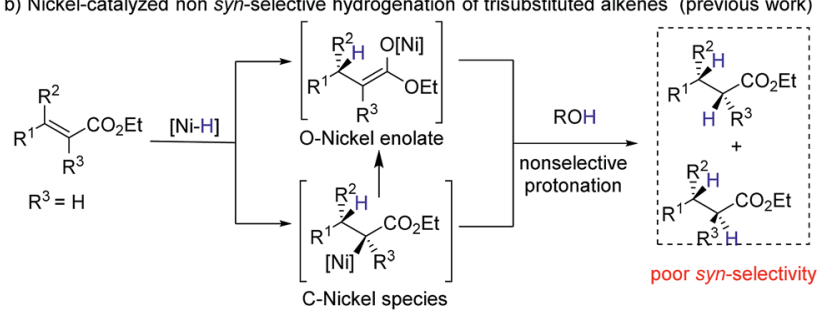

c) Nickel-catalyzed syn-selectivite hydrogenation of tetrasubstituted alkenes (this work)

$$
\begin{aligned}
& \text { Challenges: } \\
& \text { - low reactivity of tetrasubstituted electron-deficient alkenes } \\
& \text { on competition between hydrogenation and defluorination } \\
& \text { - the control of diasteroselectivity and enantioselectivity }
\end{aligned}
$$

Fig. $1 \mathrm{Ni}$-catalyzed asymmetric hydrogenation of olefins.

monohydride pathways. ${ }^{14}$ For example, hydrogenation of acrylates involves the formation of $\mathrm{O}$-nickel enolate through 1,4-conjugate addition of $\mathrm{Ni}-\mathrm{H}$ to acrylate or $\mathrm{Ni}-\mathrm{H}$ insertion to $\mathrm{C}=\mathrm{C}$ bonds and subsequent isomerization (Fig. 1b), ${ }^{5 q, s}$ and it is extremely difficult to afford stereospecific syn-addition products by the protonation. Given that the protonolysis of the carbon-metal bond may occur with retention of configuration at carbon under suitable conditions, ${ }^{15}$ we envisioned that if we could inhibit the formation of $\mathrm{O}-$ nickel species or accelerate the protonolysis of $\mathrm{C}$-nickel species by acidic solvents or acids, syn hydrogenation products would be obtained stereospecifically (Fig. 1c). Herein, we report the first example of nickel-catalyzed asymmetric hydrogenation of tetrasubstituted fluorinated enamides, giving $\alpha$-fluoro- $\beta$-amino esters with excellent diastereo- and enantioselectivities.

Initially, asymmetric hydrogenation of $(E)$-ethyl-3-acetamido-2-fluoro-3-phenylacrylate $(E)$-1a was investigated using $5 \mathrm{~mol} \% \mathrm{Ni}(\mathrm{OAc})_{2}$ and $5.5 \mathrm{~mol} \%$ ligand under 70 atm of $\mathrm{H}_{2}$ at $80{ }^{\circ} \mathrm{C}$ in $\mathrm{CF}_{3} \mathrm{CH}_{2} \mathrm{OH}$ for $24 \mathrm{~h}$. A variety of diphosphine ligands (Fig. 2) developed by our group and some commercially available chiral ligands were examined (Table 1$)$. When $\left(R_{\mathrm{C}}, S_{\mathrm{P}}\right)$ DuanPhos and $(R)$-BINAP were employed for this reaction, both of them showed excellent reactivities and enantioselectivities, but an undesired defluorination product was observed (Table 1, entries 1-2). ( $S, S)$-Me-DuPhos and $(S, S)$-Ph-BPE exhibited low catalytic activity for this transformation albeit with good enantioselectivities (Table 1, entries 3-4). To our delight, full conversion and excellent ee were obtained by using $(S)$-Binapine as the ligand (Table 1 , entry $5,>99 \%$ conversion and $>99 \%$ ee). Notably, no defluorination or diastereoisomer products were detected in this process, which indicated that the $\mathrm{Ni}(\mathrm{OAc})_{2} /(S)$ Binapine catalytic system is efficient and effective for the

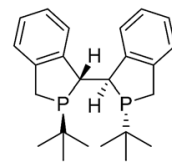

$\left(R_{\mathrm{C}}, S_{\mathrm{P}}\right)$-DuanPhos L1

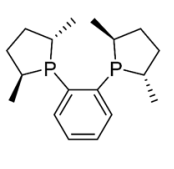

(S, S)-Me-DuPhos

L4

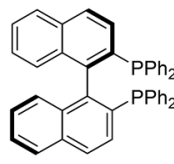

(R)-BINAP L2

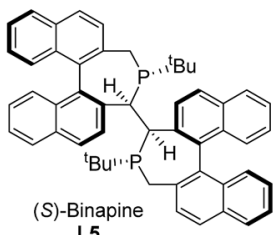

L5

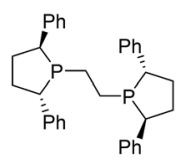

$(S, S)-P h-B P E$ L3
Fig. 2 Structures of the phosphine ligands for hydrogenation of $(E)$ ethyl-3-acetamido-2-fluoro-3-phenylacrylate (E)-1a.

\begin{tabular}{|c|c|c|c|c|c|c|}
\hline \multirow[b]{2}{*}{ Entry } & \multirow[b]{2}{*}{ Ligand } & \multirow[b]{2}{*}{ Solvent } & \multicolumn{2}{|c|}{ Yield $^{b}[\%]$} & \multirow[b]{2}{*}{$\mathbf{2 a}: 3 \mathbf{a}^{b}$} & \multirow[b]{2}{*}{$\mathrm{ee}^{c}$} \\
\hline & & & $2 a+3 a$ & $4 a$ & & \\
\hline 1 & L1 & TFE & 72 & 28 & $>99: 1$ & 97 \\
\hline 2 & L2 & TFE & 88 & 12 & $>99: 1$ & 95 \\
\hline 3 & L3 & TFE & $<10$ & 0 & $>99: 1$ & 99 \\
\hline 4 & L4 & TFE & $<10$ & 0 & $>99: 1$ & -72 \\
\hline 5 & L5 & TFE & $>99$ & 0 & $>99: 1$ & $>99$ \\
\hline 6 & L5 & Toluene & NR & NR & - & - \\
\hline 7 & L5 & THF & Trace & - & - & - \\
\hline 8 & L5 & EtOAc & Trace & - & - & - \\
\hline 9 & L5 & $\mathrm{CH}_{2} \mathrm{Cl}_{2}$ & Trace & - & - & - \\
\hline 10 & L5 & $\mathrm{MeOH}$ & 42 & 5 & $1: 2$ & $>99$ \\
\hline 11 & L5 & EtOH & 25 & 20 & $<1: 20$ & - \\
\hline $12^{d}$ & L5 & TFE & $>99$ & 0 & $>99: 1$ & $>99$ \\
\hline $13^{d, e}$ & L5 & TFE & 32 & 0 & $>99: 1$ & $>99$ \\
\hline
\end{tabular}

Table 1 Reaction condition optimization of Ni-catalyzed asymmetric hydrogenation of $(E)$-ethyl-3-acetamido-2-fluoro-3-phenylacrylate $(E)-1 a^{a}$

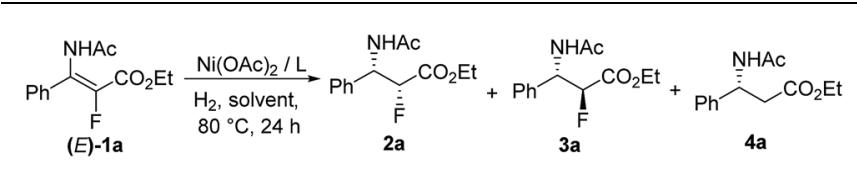

${ }^{a}$ Conditions: $\mathrm{Ni}(\mathrm{OAc})_{2} /(S)$-Binapine/(E)-1a $1: 1.1: 20$, in $0.5 \mathrm{~mL}$ of solvent. ${ }^{b}$ The conversion and ratio were determined using ${ }^{1} \mathrm{H}$ NMR analysis. ${ }^{c}$ The ee values of 2 a were determined using HPLC analysis with a chiral stationary phase. ${ }^{d} 50 \mathrm{~atm}$ of $\mathrm{H}_{2} \cdot{ }^{e} 50{ }^{\circ} \mathrm{C}$.

asymmetric hydrogenation of (E)-1a. Subsequently, the solvent effect was investigated, and the results revealed that solvents play critical roles in this reaction, affecting the catalytic activity and selectivity greatly. When toluene, tetrahydrofuran (THF), ethyl acetate (EtOAc) and dichloromethane $\left(\mathrm{CH}_{2} \mathrm{Cl}_{2}\right)$ were used as solvents, the reactions were totally inhibited or only trace products were detected (Table 1, entries 7-9). When the reactions were conducted in $\mathrm{MeOH}$ or $\mathrm{EtOH}$, the defluorination product was observed with poor yields, affording $\mathbf{3 a}$ as the major product (Table 1, entries 10-11). The effect of $\mathrm{H}_{2}$ pressure for this reaction was also evaluated. Full conversion with an unchanged ee value was obtained when the reaction was carried out in $\mathrm{CF}_{3} \mathrm{CH}_{2} \mathrm{OH}$ under a lower hydrogen pressure of $50 \mathrm{~atm}$ 
(Table 1 , entry 12). When the temperature decreased to $50{ }^{\circ} \mathrm{C}$, the reaction proceeded with $32 \%$ conversion (Table 1 , entry 13 ). Therefore, the optimized reaction conditions involved the use of $\mathrm{Ni}(\mathrm{OAc})_{2} /(S)$-Binapine as a catalyst under 50 atm of $\mathrm{H}_{2}$ pressure in $\mathrm{CF}_{3} \mathrm{CH}_{2} \mathrm{OH}$ at $80{ }^{\circ} \mathrm{C}$ for $24 \mathrm{~h}$.

With the optimized reaction conditions in hand, a series of $\beta$-enamido- $\alpha$-fluoro esters were examined to evaluate the substrate scope and generality of this catalytic reaction. As shown in Scheme 1, compounds $(E)$-1 with different ester groups were found to be good substrates to give the desired $\beta$ amido- $\alpha$-fluoro esters in excellent yields with outstanding stereocontrol ( $2 \mathbf{a}$ and $\mathbf{2 b}$ ). A wide range of $\beta$-aryl- $\beta$-enamido- $\alpha$-fluoro esters with electron-rich or -poor aryl groups were examined. High yields and excellent enantioselectivities were observed in most cases, regardless of the substitution position (2c-2k). Moreover, excellent enantioselectivity was obtained with the substrate containing the naphthyl group (2l). In addition, when the acetyl group, the protection group of the amino group, was changed to a benzoyl group, high yield and excellent enantioselectivity were also achieved (2m). Notably, when the aryl group was changed to an alkyl group, such as methyl, i-butyl, or $n$ -

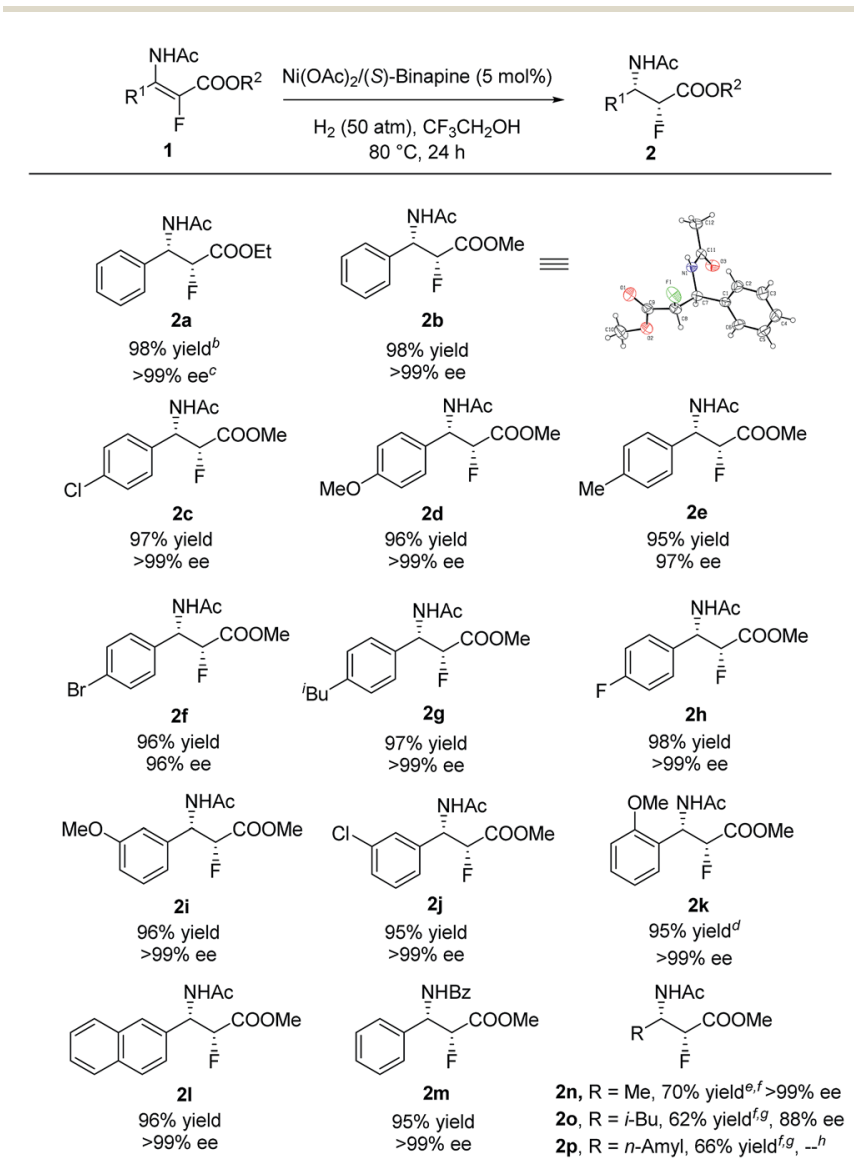

Scheme 1 Substrate scope. ${ }^{a}$ Unless otherwise mentioned, all reactions were carried out with a $\mathrm{Ni}(\mathrm{OAc})_{2} /(\mathrm{S})$-Binapine/substrate ratio of $1: 1.1: 20$, in $0.5 \mathrm{~mL}$ of $\mathrm{CF}_{3} \mathrm{CH}_{2} \mathrm{OH}$, at $80^{\circ} \mathrm{C}$, under hydrogen (50 atm) for $24 \mathrm{~h} .{ }^{b}$ Yield of the isolated product. ${ }^{\circ}$ Determined by HPLC analysis using a chiral stationary phase. ${ }^{d}$ Under $70 \mathrm{~atm}$ of $\mathrm{H}_{2} .{ }^{e}$ Under $100 \mathrm{~atm}$ of $\mathrm{H}_{2}$. ${ }^{f}$ Defluorination product was detected. ${ }^{9}$ The reaction was conducted with a $\mathrm{Ni}(\mathrm{OAc})_{2} /(S)$-Binapine/substrate ratio of $1: 1.1: 10$ under $90 \mathrm{~atm}$ of $\mathrm{H}_{2}$ at $80^{\circ} \mathrm{C}$ for $46 \mathrm{~h}$. ${ }^{h}$ The ee was not possible to detect. amyl, the reaction also proceeded smoothly, affording $\beta$-amido$\alpha$-fluoro esters with good yields and high enantioselectivities (2n-2p). Moreover, in order to determine the absolute configuration of the products, X-ray analysis of $\mathbf{2} \mathbf{b}$ was conducted, and the configuration was determined as $(2 R, 3 S) .{ }^{16}$

To obtain insight into this catalytic system, a series of isotopic labeling studies were conducted. Firstly, when $\mathbf{1 b}$ was hydrogenated with 50 atm of $\mathrm{D}_{2}$ in $\mathrm{CF}_{3} \mathrm{CH}_{2} \mathrm{OH}$ at $80{ }^{\circ} \mathrm{C}$, the deuterium atom was solely added at the $\beta$ position (Scheme $2 \mathrm{a}$ ). Then, when the experiment was carried out with 70 atm of $\mathrm{H}_{2}$ in $\mathrm{CD}_{3} \mathrm{OD}$, the deuterium atoms were incorporated at the $\alpha$ position of the ester (Scheme $2 \mathrm{~b}$ ). Finally, when $\mathbf{2 b}$ was stirred in a mixture of $1: 1 \mathrm{CD}_{3} \mathrm{OD} / \mathrm{CF}_{3} \mathrm{CH}_{2} \mathrm{OH}$ at $80{ }^{\circ} \mathrm{C}$, the deuterium atoms were found at ester and amido groups, excluding the $\mathrm{H} / \mathrm{D}$ exchange at the $\alpha$ position of the ester after the product was formed (Scheme $2 \mathrm{c}) .^{17}$

In order to ascertain the role of solvent in modulation of diastereoselectivity, we conducted this reaction in $\mathrm{MeOH}$ by adding different ratios of acetic acid (Table 2), and the results revealed that the yields and diastereoselectivities were gradually improved as the ratios of acetic acid increased. Joyfully, when 15 equivalents of acetic acid were added, only the syn hydrogenation product was obtained. These results suggested that the acidic proton plays a critical role in the control of diastereoselectivity.

Considering that the reaction was conducted at relatively high temperature, and anti-selective product 3a was the major product in ethanol or methanol, we assumed that the protonation of nickel enolate was a thermodynamically controlled process, which was beneficial for the formation of the major product with anti-selectivity. ${ }^{18}$ Based on these results and analysis, we proposed the plausible reaction pathway (Fig. 3). The heterolytic cleavage of $\mathrm{H}_{2}$ gave the $\mathrm{NiH}$ complex ${ }^{5 q, s}$ followed by reaction with enamide to form nickel intermediate I. There were two possible reaction pathways from intermediate $\mathbf{I}$. When the reaction was conducted in $\mathrm{CF}_{3} \mathrm{CH}_{2} \mathrm{OH}$, the acidity of the solvent greatly accelerated the stereospecific protonolysis of nickel species I, which led to the inhibition of conversion of $\mathbf{I}$ to II, generating the syn hydrogenation product (path A). When a less acidic solvent (methanol) was used, the reaction rate of isomerization of intermediate $\mathbf{I}$ to II was faster than

a)

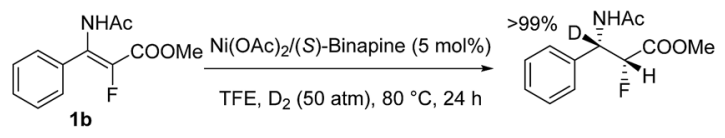

b)
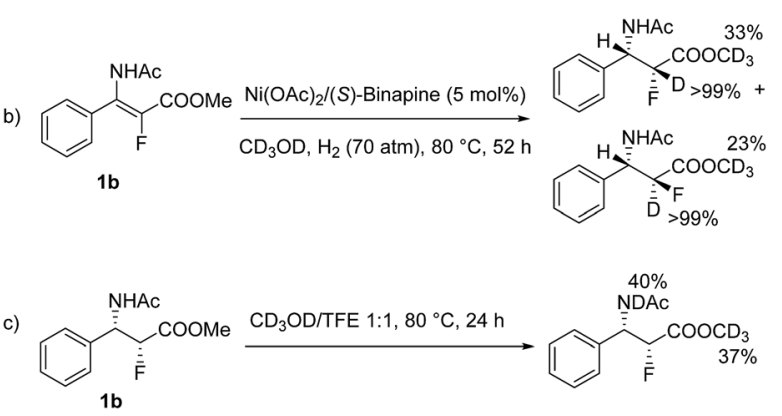

Scheme 2 Deuterium labeling studies of asymmetric hydrogenation of $1 b$. 
Table 2 Solvent effect on asymmetric hydrogenation of compound (E) $-1 a^{a}$

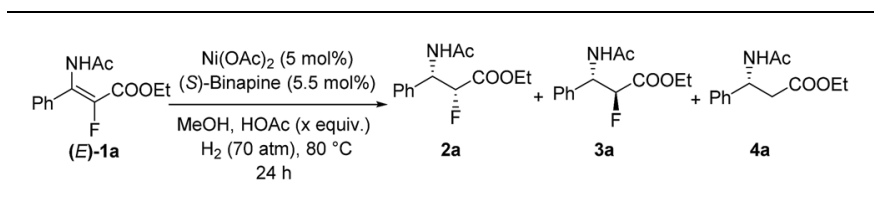

\begin{tabular}{|c|c|c|c|c|}
\hline \multirow[b]{2}{*}{ Entry } & \multirow[b]{2}{*}{ HOAc (x equiv.) } & \multicolumn{2}{|c|}{ Yield/\% } & \multirow{2}{*}{$\frac{\text { Ratio }}{2 \mathbf{a}: \mathbf{3 a}}$} \\
\hline & & $2 a+3 a$ & $4 a$ & \\
\hline 1 & - & 42 & 5 & $1: 2$ \\
\hline 2 & 0.5 & 51 & $<1$ & $1: 1$ \\
\hline 3 & 1.0 & 61 & $<1$ & $68: 32$ \\
\hline 4 & 5.0 & $>99$ & $<1$ & $93: 7$ \\
\hline 5 & 15.0 & $>99$ & 0 & $>99: 1$ \\
\hline
\end{tabular}

a All reactions were carried out with a $\mathrm{Ni}(\mathrm{OAc})_{2} /(S)$-Binapine/substrate ratio of $1: 1.1: 20$, in $0.5 \mathrm{~mL}$ of $\mathrm{CF}_{3} \mathrm{CH}_{2} \mathrm{OH}$, at $80^{\circ} \mathrm{C}$, under hydrogen (70 atm) for $24 \mathrm{~h}$.

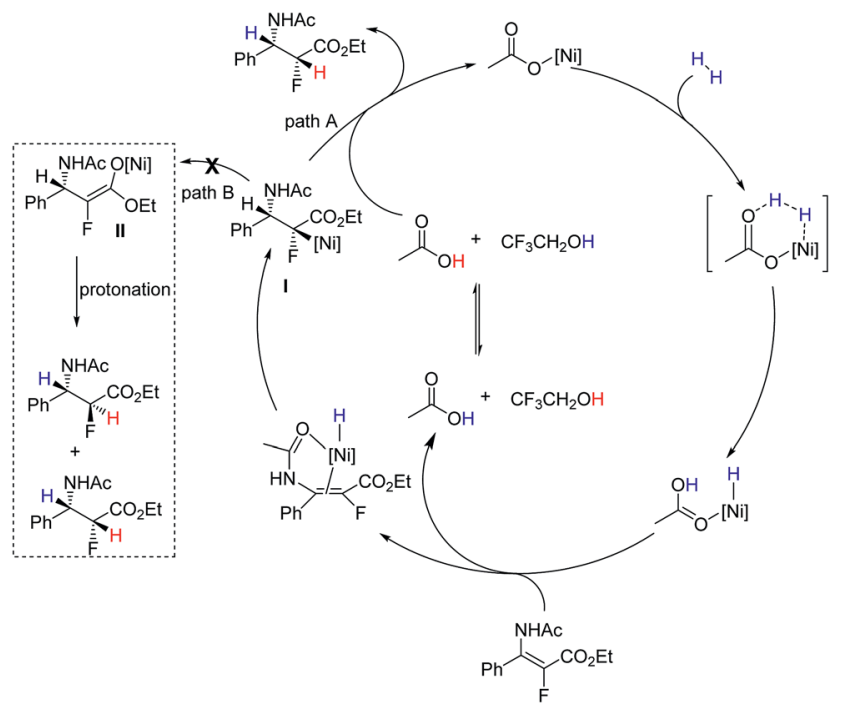

Fig. 3 Proposed mechanism.

protonolysis of intermediate I, thus forming nickel enolate II preferentially; then II underwent protonation to afford anti/syn mixed products (path B). Both pathways coexisted in methanol; therefore the ratio of anti/syn is poor. The thermodynamic protonation is the predominant pathway in ethanol, which resulted in a high ratio of anti/syn.

To demonstrate the potential utility of this methodology, asymmetric hydrogenation of $(E)$-1b was performed on a gram

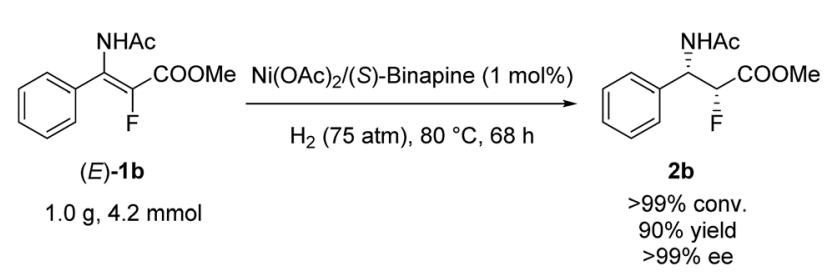

Scheme 3 Gram-scale reaction. scale with 1 mol\% catalyst loading, and the desired product (2b) was obtained with $90 \%$ yield and $>99 \%$ ee (Scheme 3 ).

\section{Conclusions}

In conclusion, a $\mathrm{Ni}(\mathrm{OAc})_{2} /(S)$-Binapine complex catalyzed asymmetric hydrogenation of tetrasubstituted $\beta$-enamido- $\alpha$-fluoro esters has been achieved in high yields with excellent diastereoand enantioselectivities (up to $98 \%$ yield, up to $>99 \%$ ee, and up to $>99: 1 \mathrm{dr}$ ). More importantly, this investigation reveals the critical role of acidic solvent in modulating the reaction pathway and in the control of diastereoselectivity, which throws a new light on the reaction mechanism. This method features a broad substrate scope, excellent stereoselectivity and diastereoselectivity, and provides an efficient and concise route to $\alpha$ fluoro- $\beta$-amino esters. Further investigations on nickel-catalyzed asymmetric hydrogenation are in progress in our lab.

\section{Conflicts of interest}

There are no conflicts to declare.

\section{Acknowledgements}

We are grateful for financial support from the National Natural Science Foundation of China (Grant No. 21871212, 21402145 and 21432007), the Natural Science Foundation of Hubei Province (2018CFB430), the Fundamental Research Funds for the Central Universities (2042017kf0177), the Important SciTech Innovative Project of Hubei Province (2015ACA058) and the "111" Project of the Ministry of Education of China.

\section{Notes and references}

1 (a) W. S. Knowles, Acc. Chem. Res., 1983, 16, 106; (b) R. Noyori and S. Hashiguchi, Acc. Chem. Res., 1997, 30, 97; (c) Q.-H. Fan, Y.-M. Li and A. S.-C. Chan, Chem. Rev., 2002, 102, 3385; (d) W.-J. Tang and X.-M. Zhang, Chem. Rev., 2003, 103, 3029; (e) I. D. Gridnev and T. Imamoto, Acc. Chem. Res., 2004, 37, 633; (f) S. J. Roseblade and A. Pfaltz, Acc. Chem. Res., 2007, 40, 1402; (g) Y.-G. Zhou, Acc. Chem. Res., 2007, 40, 1357; $(h)$ H. Shimizu, I. Nagasski, K. Matsumura, N. Sayo and T. Saito, Acc. Chem. Res., 2007, 40, 1385; (i) W. Zhang, Y. Chi and X.-M. Zhang, Acc. Chem. Res., 2007, 40, 1278; (j) J.-H. Xie, S.-F. Zhu and Q.-L. Zhou, Chem. Rev., 2011, 111, 1713; $(k)$ Y. Liu, Z. Wang and K.-L. Ding, Acta Chim. Sin., 2012, 70, 1464; (l) J.-H. Xie and Q.-L. Zhou, Acta Chim. Sin., 2012, 70, 1427; $(m)$ B.-G. Zhao, Z.-B. Han and K.-L. Ding, Angew. Chem., Int. Ed., 2013, 52, 4744; (n) Y.-M. He, Y. Feng and Q.-H. Fan, Acc. Chem. Res., 2014, 47, 2894; (o) Z.-F. Zhang, N. A. Butt and W.-B. Zhang, Chem. Rev., 2016, 116, 14769.

2 S. Kraft, K. Ryan and R. B. Kargbo, J. Am. Chem. Soc., 2017, 139, 11630.

3 P. J. Chirik, Acc. Chem. Res., 2015, 48, 1687.

4 R. H. Morris, Acc. Chem. Res., 2015, 48, 1494.

5 (a) R. H. Morris, Chem. Soc. Rev., 2009, 38, 2282; (b) Y. Y. Li, S. L. Yu, W. Y. Shen and J. X. Gao, Acc. Chem. Res., 2015, 48, 
2587; (c) R. H. Morris, Acc. Chem. Res., 2015, 48, 1494; (d) R. Bigler, R. Huber and A. Mezzetti, Angew. Chem., Int. Ed., 2015, 54, 5171; (e) J. F. Sonnenberg, K. Y. Wan, P. E. Sues and R. H. Morris, ACS Catal., 2017, 7, 316; (f) S. Monfette, Z. R. Turner, S. P. Semproni and P. J. Chirik, J. Am. Chem. Soc., 2012, 134, 4561; $(g)$ M. R. Friedfeld, M. Shevlin, J. M. Hoyt, S. W. Krska, M. T. Tudge and P. J. Chirik, Science, 2013, 342, 1076; (h) M. R. Friedfeld, M. Shevlin, G. W. Margulieux, L. Campeau and P. J. Chirik, J. Am. Chem. Soc., 2016, 138, 3314; (i) J. H. Chen, C. H. Chen, C. L. Ji and Z. Lu, Org. Lett., 2016, 18, 1594; (j) G. R. Morello, H. Zhong, P. J. Chirik and K. H. Hopmann, Chem. Sci., 2018, 9, 4977; (k) J. Chen and Z. Lu, Org. Chem. Front., 2018, 5, 260; (l) Y. Hamada, Y. Koseki, T. Fujii, T. Maeda, T. Hibino and K. Makino, Chem. Commun., 2008, 6206; $(\mathrm{m}) \mathrm{P}$. Yang, H. Y. Xu and J. R. Zhou, Angew. Chem., Int. Ed., 2014, 53, 12210; (n) S. Y. Guo, P. Yang and J. R. Zhou, Chem. Commun., 2015, 51, 12115; (o) H. Y. Xu, P. Yang, P. Chuanprasit, H. Hirao and J. R. Zhou, Angew. Chem., Int. Ed., 2015, 54, 5112; (p) P. Yang, L. H. Lim, P. Chuanprasit, H. Hirao and J. R. Zhou, Angew. Chem., Int. Ed., 2016, 55, 12083; (q) M. Shevlin, M. R. Friedfeld, H. Sheng, N. A. Pierson, J. M. Hoyt, L. Campeau and P. J. Chirik, J. Am. Chem. Soc., 2016, 138, 3562; (r) S. Y. Guo and J. R. Zhou, Org. Lett., 2016, 18, 5344; $(s)$ W. Gao, H. Lv, T. Zhang, Y. Yang, L. W. Chung, Y.-D. Wu and X. Zhang, Chem. Sci., 2017, 8, 6419; $(t)$ X. Li, C. You, S. Li, H. Lv and X. Zhang, Org. Lett., 2017, 19, 5130; (u) M. R. Friedfeld, H. Zhong, R. T. Ruck, M. Shevlin and P. J. Chirik, Science, 2018, 360, 888; (v) Z. Zhang, N. A. Butt, M. Zhou, D. Liu and W. Zhang, Chin. J. Chem., 2018, 36, 443.

6 (a) E. P. Gillis, K. J. Eastman, M. D. Hill, D. J. Donnelly and N. A. Meanwell, J. Med. Chem., 2015, 58, 8315; (b) J. Wang, M. Sanchez-Rosello, J. L. Acena, C. del Pozo, A. E. Sorochinsky, S. Fustero, V. A. Soloshonok and H. Liu, Chem. Rev., 2014, 114, 2432; (c) K. Mikami, Y. Itoh and M. Yamanaka, Chem. Rev., 2004, 104, 1.

7 K. Mueller, C. Faeh and F. Diederich, Science, 2007, 317, 1881. 8 (a) C. D. Cox and R. M. Garbaccio, Adv. Anticancer Agents Med. Chem., 2013, 1, 269; (b) A. D. Ajavon, P. L. Bonate and D. R. Taft, Eur. J. Pharm. Sci., 2010, 40, 209; (c) R. S. Obach, F. Lombardo and N. J. Waters, Drug Metab. Dispos., 2008, 36, 1385.

9 (a) N. Shibata, E. Suzuki and Y. Takeuchi, J. Am. Chem. Soc., 2000, 122, 10728; (b) D. Cahard, C. Audouard, J.-C. Plaquevent and N. Roques, Org. Lett., 2000, 2, 3699; (c) M. Marigo, D. Fielenbach, A. Braunton, A. Kjærsgaard and K. A. Jørgensen, Angew. Chem., Int. Ed., 2005, 44, 3703; (d) D. D. Steiner, N. Mase and C. F. Barbas III, Angew. Chem., Int. Ed., 2005, 44, 3706; (e) T. D. Beeson and D. W. C. MacMillan, J. Am. Chem. Soc., 2005, 127, 8826; (f) M. L. Schulte and C. W. Lindsley, Org. Lett., 2011, 13, 5684; (g) C. Appayee and S. E. Brenner-Moyer, Org. Lett., 2010, 12, 3356; (h) Y.-Y. Huang, X. Yang, Z. Chen, F. Verpoort and N. Shibata, Chem.-Eur. J., 2015, 21, 8664.

10 (a) W. Kong, P. Feige, T. de Haro and C. Nevado, Angew. Chem., Int. Ed., 2013, 52, 2469; (b) T. Honjo, R. J. Phipps, V. Rauniyar and F. D. Toste, Angew. Chem., Int. Ed., 2012,
51, 9684; (c) R. J. Phipps, K. Hiramatsu and F. D. Toste, J. Am. Chem. Soc., 2012, 134, 8376; (d) O. Lozano, G. Blessley, T. Martinez del Campo, A. L. Thompson, G. T. Giuffredi, M. Bettati, M. Walker, R. Borman and V. Gouverneur, Angew. Chem., Int. Ed., 2011, 50, 8105; (e) D.-F. Lu, C.-L. Zhu, J. D. Sears and H. Xu, J. Am. Chem. Soc., 2016, 138, 11360; $(f)$ K. M. Mennie, S. M. Banik, E. C. Reichert and E. N. Jacobsen, J. Am. Chem. Soc., 2018, 140, 4797.

11 (a) D. Cahard, X. Xu, S. Couve-Bonnaire and X. Pannecoucke, Chem. Soc. Rev., 2010, 39, 558; (b) X. Yang, T. Wu, R. J. Phipps and F. D. Toste, Chem. Rev., 2015, 115, 826; (c) Z. Jiao, J. J. Beiger, Y. Jin, S. Ge, J. S. Zhou and J. F. Hartwig, J. Am. Chem. Soc., 2016, 138, 15980.

12 (a) M. Engman, J. S. Diesen, A. Paptchikhine and P. G. Andersson, J. Am. Chem. Soc., 2007, 129, 4536; (b) P. Zhang, C. Wang, L. Zhou and J. Sun, Chin. J. Chem., 2012, 30, 2636.

13 D. M. Sedgwick and G. B. Hammond, J. Fluorine Chem., 2018, 207, 45.

14 (a) I. D. Gridnev, N. Higashi, K. Asakura and T. Imamoto, J. Am. Chem. Soc., 2000, 122, 7183; (b) R. Giernoth, H. Heinrich, N. J. Adams, R. J. Deeth, J. Bargon and J. M. Brown, J. Am. Chem. Soc., 2000, 122, 12381; (c) A. S. C. Chan, J. J. Pluth and J. Halpern, J. Am. Chem. Soc., 1980, 102, 5952; (d) J. M. Brown and P. A. Chaloner, J. Chem. Soc., Chem. Commun., 1980, 344; (e) M. Kitamura, M. Tsukamoto, Y. Bessho, M. Yoshimura, U. Kobs, M. Widhalm and R. Noyori, J. Am. Chem. Soc., 2002, 124, 6649. 15 (a) H. Qian and R. A. Widenhoefer, J. Am. Chem. Soc., 2003, 125, 2056; (b) H. Qian, T. Pei and R. A. Widenhoefer, Organometallics, 2005, 24, 287.

16 The X-ray crystal data for $\mathbf{2 b}$ have been deposited with the Cambridge Crystallographic Data Centre as supplementary publication no. CCDC 1845389. $\dagger$

17 The difference in the deuterium labelling ratio of the NHAc group in Scheme $2 \mathrm{~b}$ and $\mathrm{c}$ may be attributed to the different purification procedures. In Scheme $2 \mathrm{~b}$, deuterium exchange between the NDAc and trace water in the eluent might occur in column chromatography; thus no NDAc was detected in NMR experiments.

18 Although the kinetic protonation of nickel enolate can explain the formation of the syn-product in $\mathrm{CF}_{3} \mathrm{CH}_{2} \mathrm{OH}$, it can't account for the experimental results in ethanol or methanol. In addition, it also can't explain why the syn/ anti ratio of the product improved as the acidity of solvent increased. Thus, it is excluded.

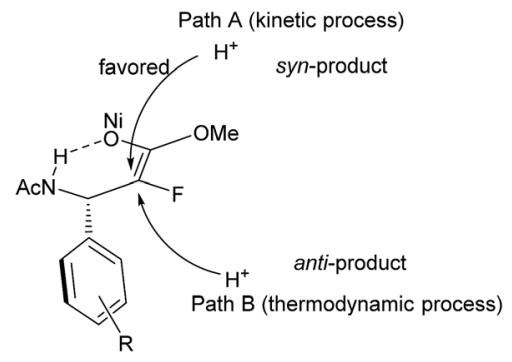

